\title{
E-commerce - Quais ícones e metáforas são a alma do negócio?
}

\author{
Fábio Pio, Cayley Guimarães \\ Departamento de Ciências Exatas e Tecnológicas - Centro Universitário de Belo \\ Horizonte (UNI-BH), Belo Horizonte - MG - Brasil \\ fabiopio@gmail.com, profcayley@yahoo.com.br
}

\begin{abstract}
Cultural differences may affect how individual perceive and attribute meanings to icons and metaphors. The appropriate use of metaphors and iconic interfaces may reduce complexity, thus increasing usability. Meaningful and identifiable icons should be used when designing e-commerce sites. If an e-commerce site is to be used by international customers, culture should be taken into consideration. The same set of Icons tested in an American study was tested with Brazilian students. Following, a new set, this time formed with icons from Brazilian e-commerce web sites, was tested. Few Icons were "identifiable", which led us to build a prototype and perform a user test to determine a common set of easily "identifiable" icons.
\end{abstract}

Key Words: Usability, E-commerce, Icons

Resumo. Diferenças culturais podem afetar a maneira como indivíduos percebem e atribuem significados aos ícones e metáforas. O uso apropriado de metáforas e ícones significativos e identificáveis pode reduzir a complexidade, aumentando a usabilidade; e devem ser usados ao se projetar sites de e-commerce. Se o site for para uso de clientes internacionais, as diferenças culturais devem ser consideradas. O mesmo conjunto de ícones de um estudo americano foi testado com brasileiros. Depois, um novo conjunto, formado por ícones de sites brasileiros, foi testado com brasileiros. Encontraram-se discrepâncias. Então, construiu-se um protótipo com os ícones mais significativos; realizaram-se testes com usuários para se determinar um conjunto de ícones mais facilmente "identificáveis”.

Palavras-Chave: Usabilidade, E-commerce, Ícones

\section{Introdução:}

A revolução provocada pelas novas Tecnologias de Informação e comunicação (TICs) transformaram a sociedade em Sociedade da Informação e do Conhecimento, que se caracteriza por novas formas de se realizar as atividades humanas, dentre elas o comércio. A Internet é o expoente mais visível desta nova sociedade, e se apresenta como o canal por excelência para as relações de troca: a cada dia cresce o número de sites de comércio eletrônico, ou e-commerce, e cresce também a quantidade de usuários que deles se valem para comprar os mais diversos produtos e serviços, tanto físicos (CD’s, livros, computadores etc.) quanto virtuais (música, filme, consultorias, etc.). 
No mundo globalizado, os usuários encontram-se dispersos no tempo e no espaço geográfico, e, principalmente, nas mais diversas nacionalidades e culturas. A usabilidade do site torna-se importante, pois não só ela é testada antes da compra do produto (diferentemente da loja, em que a usabilidade do produto é testada quando o usuário chega em casa; a usabilidade do site é um fator, antes mesmo do cliente comprar o produto), como a falta de usabilidade pode impedir a realização da tarefa. Uma maneira de melhorar a usabilidade é o uso de metáforas.

Os sites de e-commerce usam metáforas (semelhanças entre elementos) e ícones (figuras) para facilitar a vida do usuário [Carroll \& Moran 1996]. Estes elementos servem para realizar tarefas, conferir funções, fazer pedidos, especificar serviços, recuperar informações, entre outras. Um exemplo muito comum deste uso em sites de ecommerce é o ícone "carrinho de compras" para "guardar" os produtos selecionados, a serem comprados.

No entanto, transmitir o significado desejado não é tarefa fácil, e nem sempre ocorre com os ícones [Rogers 1986]. Norman (2007) alerta que um ícone que não é bem interpretado pode levar o usuário a achar que o sistema tem funções que na verdade não estão lá. E, quando este símbolo é acessado por usuários de uma cultura diferente, a atribuição de significado pode ser mais diversa ainda. Este problema afeta o uso, e, consequentemente, a compra/venda. $\mathrm{O}$ desenvolvedor de site de comércio eletrônico deve levar em conta o significado dos ícones e metáforas nas diversas culturas de usuários, uma vez que os acessos aos mesmos hoje são mundiais.

Este estudo se vale do mesmo conjunto de ícones de um estudo americano [Cheng \& Patterson 2006] e verifica a não-conformidade dos resultados no contexto cultural de brasileiros. Posteriormente, construiu-se um conjunto de ícones de sites de ecommerce brasileiros para comparação. Finalmente, construiu-se um protótipo de site de e-commerce com os ícones mais significativos; este conjunto contém ícones tanto de sites americanos quanto de sites brasileiros. Testou-se este protótipo, com pesquisados realizando tarefas típicas em sites de e-commerce, com o objetivo de obtenção de um denominador comum de ícones significativos.

\section{Usabilidade:}

De acordo com Scapin (1993), usabilidade envolve a habilidade do sistema em permitir que seus usuários sejam capazes de atingir facilmente seus objetivos de interação com o sistema. Em suma, é um usuário (comprador) usando um sistema (o site de e-commerce) para realizar uma tarefa (comprar).

Carroll e Moran (1996) acrescentam dizendo que as principais características necessárias a um sistema para apresentar uma boa usabilidade são: facilidade de uso; fácil entendimento de como operar o mesmo para a execução da tarefa desejada; ter sucesso na execução das tarefas; percepção dos erros e recuperação dos mesmos.

O ser humano deve ser, em última análise, o objetivo final de qualquer tecnologia, e, portanto, uma boa interação entre o Sistema de Informação e o usuário é de fundamental importância. Segue-se que o design deve levar em conta a atividade a ser realizada, o usuário que vai executar a tarefa e o contexto social do mesmo, para que a interação seja a mais adequada possível. Caso estes preceitos não estejam presentes, 
corre-se o risco do sistema não atingir o seu objetivo. Se não se tem usabilidade, não se vende. E o concorrente está a menos de um "click do mouse".

\section{Metáforas e ícones:}

Pode-se imaginar que para o usuário, a interface "é" o sistema, em que tudo no monitor são superfícies e símbolos, e estes são os elementos com os quais ele lida. E estes elementos são decifrados, na prática, por conta e risco do usuário. Ao se trabalhar com metáforas, busca-se apresentar ao usuário semelhanças entre elementos do computador e outras realidades que lhe sejam familiares (e.g. o teclado pode ser associado a uma máquina de escrever) para facilitar este processo de entendimento e uso do novo sistema; as metáforas auxiliam o usuário na atribuição de significados ao novo.

Elas podem ser estruturais (ao compararem um conceito a outro - céu azul significa tudo tranqüilo no Brasil, para o americano blue significa "triste"); orientacionais (com função de orientação espacial - setas); convencionais (baseadas no que já é intuitivo - ponto de interrogação para ajuda); ou ontológicas (que relacionam conceitos com objetos). A imagem que representa o conceito de maneira não-verbal pode ter características de semelhança (pictografias), analogia (símbolo) ou costume social (signo) [Standing et al. 1970].

Estas últimas metáforas, que nos fornecem interfaces pictográficas (ícones ou símbolos), físicas, têm como objetivo, portanto, tornar o software mais amigável. Elas podem reduzir a complexidade do sistema e a carga mental do usuário [Lodding 1983]; podem representar comandos, funções ou estados do sistema - sendo que o ícone mais efetivo é o que mapeia o objeto diretamente. [Rogers 1986]; são mais facilmente reconhecíveis e lembradas [Standing et al. 1970].

\section{Nem todas as metáforas funcionam do mesmo jeito, principalmente em culturas diferentes:}

A percepção humana é influenciada pelo contexto cultural, pelo contexto social e pelo contexto lingüístico, incluindo diferenças culturais na maneira como as pessoas interagem com os computadores. Como a interface é cultural, os signos, como meio de uma mensagem a ser transmitida, devem ser significantes à cultura a que pretendem levar informação [Pontes \& Orth 2001]. Projetos que se pretendem globais, como os sites de e-commerce, devem levar em conta as especificidades de usos, uma vez que os signos não têm valor único e geral. Uma metáfora mal elaborada, não entendida, pode custar uma transação comercial.

Como exemplos de diferenças culturais, temos Nisbett \& Chua (2005), que mostram que os asiáticos tendem a ver uma imagem no seu conjunto, prestando atenção ao que está em primeiro plano e no fundo, enquanto os americanos demoram mais o olhar no objeto central de um quadro. Este achado pode ser usado na forma de se apresentar um produto no site de e-commerce, por exemplo.

Guimarães (2000) alerta que a localização do preço do produto influencia diretamente na sua compra: por exemplo, se site apresentar a descrição do produto primeiro, e o preço no final, os americanos, que lêem da esquerda para direita e do topo para baixo, veriam a descrição do produto antes do preço, relativizando-o; já os 
asiáticos, que lêem da direita para esquerda, de baixo para o topo, veriam o preço antes, podendo assim não levar em conta as características do produto.

Yuki (2007) mostra que americanos e japoneses expressam alegria e tristeza por meio de seus teclados nos chats usando símbolos diferentes, refletindo traços culturais dos povos, apesar da integração promovida pela internet. Em decorrência, atenção redobrada deve ser tomada, pois um símbolo usado inadequadamente pode expressar idéias opostas para o consumidor.

Um exemplo típico é o de envio de e-mail, que é internacional. Porém, o uso da "caixa de correio", cujo símbolo é usado no popular sistema operacional, é comum e um ícone na cultura americana. Porém, ela pode não ter significado algum em outras culturas. Um envelope poderia ser um signo mais adequado. Mas, mesmo assim, cada país tem um padrão de envelope diferente.

A mesma idéia se aplica à "lata de lixo", tipicamente americana, que eventualmente foi substituída por uma cesta, mais universal. No Brasil, que tal o uso do nosso popular "saco de lixo" preto? Isto no que se refere ao reconhecimento da imagem, pois, observa-se uma quebra de metáfora ao se jogar fora um arquivo que na verdade se deseja apagar (que tal uma borracha?).

Outro exemplo da cultura americana é o uso de uma casa (“home”) para representar a página inicial/principal: ela serve para os americanos devido à língua Inglesa, uma vez que esta página inicial é denominada "homepage”. Para os falantes de língua Portuguesa, podemos concordar que o ícone da casa não é tão intuitivo assim.

Poucas pesquisas, e, pior, poucos sites de e-commerce levam em conta estas diferenças culturais. Cultura pode ser aqui entendida como as relações e percepções do homem no seu meio cultural. Os sites de e-commerce têm que se adequar culturalmente, para se fazer entendidos, com o objetivo de poder vender e não agredir uma cultura. Esta adequação deve ser o ponto de partida para o sucesso dos sites de e-commerce [Pontes \& Orth 2001].

\section{Pesquisa de Usabilidade:}

Este estudo procura averiguar se os achados de ícones identificáveis em uma pesquisa com americanos se reproduziriam com brasileiros, e foi realizado em duas partes. Na parte I, usou-se o mesmo conjunto de ícones e reproduziu-se a metodologia do estudo original [Cheng \& Patterson 2006]. Depois, criou-se um outro conjunto de ícones, desta vez obtidos de sites de e-commerce brasileiros, e repetiu-se a metodologia. Para a parte II da pesquisa, criou-se um protótipo com os ícones mais reconhecidos, que foi testado com um grupo diferente, executando tarefas típicas de sites de e-commerce. Finalmente, para a parte III, um terceiro grupo foi testado usando-se as tarefas da parte II em dois dos maiores sites de e-commerce brasileiros.

\subsection{Universo de pesquisa}

As estatísticas sobre o universo de empresas de e-commerce no Brasil é ainda dispersa e desencontrada, mas aponta para um volume crescente de transações, de usuários e de faturamento. Segundo Guimarães (2006) o faturamento no primeiro semestre de 2006 foi de R \$ 3,9 bilhões, comparados com R \$ 2,5 bilhões do mesmo período de 2005. O 
número de usuários em 2005 foi de 4,7milhões. A idade destes usuários: de 18 a 24 anos (14\%), de 25 a 34 anos (34\%) e de 35 a 49 anos (37\%). CDs e DVDs corresponderam a $21 \%$, das compras, livros (18\%), eletrônicos (9\%), saúde e beleza (8\%), Informática (7\%) e outros (37\%).

Pallotta (2007) projeta o faturamento de 2007 em R\$ 17,4 bilhões, comparados com R\$ 13,3 bilhões de 2006. Quanto à previsão de compras nos próximos 12 meses, 98\% de compradores pretendem voltar a comprar. E $80 \%$ de não-compradores pretendem comprar nos próximos 12 meses.

CAMARA-E. NET (2007) aponta que os gastos do $1^{\circ}$ trimestre de 2007 com bens de consumo, turismo e automóveis pela Internet somaram R 4,4 bilhões, com um aumento de $57 \%$ no faturamento comparado ao período anterior. O estudo aponta ainda um número de 5,7 milhões de usuários, um crescimento de $20 \%$ em relação a março de 2006.

Estes números mostram a importância crescente de negócios realizados em sites de e-commerce. E cabe aos desenvolvedores destes Sistemas de Informação torná-los cada vez mais atrativos para aumentar ainda mais as transações. A usabilidade ganhou status de primazia na economia da Internet [Nielsen 1999]. A ciência contribui com estudos que melhoram a usabilidade, promovendo o uso destes sites.

\subsection{Realização de testes - Parte I:}

Aproveitando-se do meio acadêmico no qual esta pesquisa se desenvolveu, reuniram-se 50 voluntários, todos alunos do último ano do curso de Ciência da Computação do UNIBH, com idades entre 18 e 28 anos. Todos já haviam feito compras em sites de ecommerce. Este grupo, sofisticado no uso de tecnologia, pode introduzir um viés no resultado da pesquisa; mas a comprovação da falta de usabilidade para um grupo com habilidade computacional acima da média pode até mesmo reforçar a tese defendida, uma vez que, se os ícones não são facilmente identificáveis para eles, provavelmente terão ainda menos significado para um usuário comum.

O experimento foi feito com dois conjuntos de ícones: um, reproduzido da pesquisa de Cheng \& Patterson (2006), de sites de e-commerce americanos, testados com americanos. Usou-se este conjunto para teste com brasileiros, para efeito de comparação; O outro conjunto foi formado de ícones obtidos de sites de e-commerce brasileiros, e testados com brasileiros. Seguiu-se a metodologia de Cheng \& Patterson (2006):

“O objetivo [...] era [é] determinar a qualidade dos ícones estudando a habilidade dos sujeitos dos testes de facilmente identificar as suas funções. Sites de ecommerce [...]. Os sujeitos dos testes foram apresentados com estes ícones e pedidos para identificar a função de cada ícone. Os sujeitos dos testes foram informados que os ícones foram coletados de sites de e-commerce”. [Cheng \& Patterson 2006] (p.66 tradução livre dos autores).

\subsection{Resultados:}

Os resultados levaram à classificação dos ícones em três grupos, de acordo com o percentual de acertos: "identificáveis" (60-100\%), "médio" (30-60\%), e "vago" (030\%); esta classificação foi feita a partir das respostas dos americanos [Cheng \& 
Patterson 2006]. O teste feito com brasileiros com ícones de site e-commerce americanos (veja tabela 1) mostra que o brasileiro encontra menos significados para os ícones apresentados, de uma maneira geral; Em alguns casos, os brasileiros não foram capazes de atribuir qualquer significado ao ícone, como no caso do ícone "meus pedidos”. Contudo, os brasileiros apresentam empatia com uma boa parte dos ícones, apesar destes não fazerem parte da sua cultura. Com o ícone de duas palmeiras, por exemplo, os brasileiros sugeriram que uma classificação relacionada com uma situação de lazer seria mais adequada do que uma relacionada com a venda de um pacote de férias. É interessante notar que alguns dos ícones americanos classificados como vagos fizeram mais sentido aos brasileiros, como os ícones para "meus pedidos" e para “catálogos”, por exemplo.

Tabela 1. Resultados de americanos e brasileiros com ícones americanos.

\begin{tabular}{|c|c|c|c|}
\hline Ícone & Função * & $\%$ Acertos Americanos & \% Acertos Brasileiros \\
\hline \multicolumn{4}{|c|}{ Identificáveis } \\
\hline 3 & Ajuda & 92.1 & 100 \\
\hline 春 & Enviar email & 86.6 & 77.4 \\
\hline & Meus pedidos & 81.6 & 67.7 \\
\hline & Site Seguro & 76.3 & 67.7 \\
\hline 早 & Meus pedidos & 71.1 & 58.1 \\
\hline & Meus pedidos & 60.5 & 0 \\
\hline 0 & Site Seguro & 60.5 & 51.6 \\
\hline \multicolumn{4}{|c|}{ Médio } \\
\hline 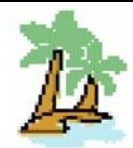 & Pacote de férias & 57.9 & 9.6 \\
\hline & Passagem aérea & 55.3 & 61.3 \\
\hline & Informações & 55.26 & 64.5 \\
\hline & Reservas em hotel & 42.1 & 32.3 \\
\hline 1 & Meus pedidos & 13.2 & 32.3 \\
\hline \multicolumn{4}{|c|}{ Vagos } \\
\hline & Meus pedidos & 2.63 & 12.9 \\
\hline$\Rightarrow$ & Situação do pedido & 15.8 & 3.2 \\
\hline & SAC & 7.8 & 29 \\
\hline & Lista de desejos & 5.3 & 0 \\
\hline++1 & Página de registro & 5.3 & 0 \\
\hline
\end{tabular}


Lista de desejos

Checar conta /

Situação do pedido

Checar conta

Checar conta

* [Cheng \& Patterson 2006] (p.67 - tradução livre dos autores).

O teste feito com ícones de sites de e-commerce brasileiros (veja tabela 2) mostra que os ícones usados pelos desenvolvedores não foram entendidos pelos usuários. Apenas dois deles foram classificados como “identificáveis”. Nota-se mesmo um grande número de ícones para os quais os pesquisados não conseguiram atribuir qualquer significado. $\mathrm{Na}$ maioria dos casos, a percentagem de sugestões (coluna “\% 2 melhor opção" da tabela 2 abaixo) foi bem superior se comparado à percentagem de acertos, fazendo com que o índice de ícones classificados como “identificáveis” e "médios" tenha ficado baixo. Essa diferença nos leva a questionar os verdadeiros significados que esses ícones tentam mostrar.

Tabela 2. Resultados de brasileiros com ícones brasileiros.

\begin{tabular}{|c|c|c|c|}
\hline Ícone & Função & $\%$ Acertos & \% $2^{\mathrm{a}}$ Melhor opção \\
\hline \multicolumn{4}{|c|}{ Identificáveis } \\
\hline & Site seguro & 84.2 & Lista de produtos (10.5) \\
\hline 圄 & Lista de produtos & 63.1 & Não houve \\
\hline \multicolumn{4}{|c|}{ Médio } \\
\hline & Lista de produtos & 52.6 & Comprar (26.3) \\
\hline & Comprar & 42.1 & Lista de produtos (52.6) \\
\hline & Serviço de entrega & 31.8 & Página inicial (36.8) \\
\hline & Site seguro & 31.8 & Não houve \\
\hline \multicolumn{4}{|c|}{$\underline{\text { Vagos }}$} \\
\hline & Ajuda on-line & 26.3 & Informações (26.3) \\
\hline & Formas de pagamento & 26.3 & Valor (52.6) \\
\hline
\end{tabular}


Embrulhar

Ajuda on-line

Ampliar foto do produto

Lista de casamentos

Localização das lojas

Política de privacidade

Itens do produto

Dados técnicos

Trocas e devoluções

Login

Vales e cupons

Disponibilidade

Televendas

Promoções e serviços

Lista de desejos

Atendimento email

Parcerias

Atendimento telefone

Descrição do produto

Ajuda

Serviços
15.8

15.8

15.8

10.5

5.3

0

$0 \quad$ Lista de produtos (68.4)

0

0

0

0

0

0

0

0

0

0

0

0

0

0

Presentear (47.4)

Contato (36.8)

Pesquisar (73.7)

Presentear (15.8)

Estoque (31.6)

Site Seguro (100)

Configurações (26.4)

Comprar (15.8)

Grupo (21.1)

Presentear (42.1)

Lacrado (5.3)

SAC (68.4)

Utilidades (26.3)

Lista de produtos (31.8)

Ajuda (94.7)

Site Seguro (47.6)

Perfil (21.1)

Salvar (31.6)

Computadores (31.6)

Lista de produtos (26.3)

\subsection{Realização de testes - Parte II:}

Na parte II da pesquisa, 46 voluntários, distintos dos voluntários da parte I, foram solicitados a realizar um conjunto de tarefas típicas de sites de e-commerce (veja tabela 3 abaixo). Estes voluntários são alunos do último ano do curso de Ciência da Computação do UNI-BH, com idades entre 18 e 28 anos, que já haviam feito compras em sites de e-commerce.

O experimento foi feito usando um protótipo de site de e-commerce construído com conjuntos de ícones “identificáveis” (de 60 a 100\% de acerto), obtidos da parte I. O objetivo era determinar se os ícones apontados como "identificáveis” assim o eram em 
uma simulação de execução de tarefa em site de e-commerce. Os pesquisados foram apresentados com uma tarefa e pedidos para identificar o ícone que realizaria a função desejada. Os pesquisados foram informados que os ícones tinham sido coletados de sites de e-commerce, sem, contudo se especificar a origem dos mesmos.

\subsection{Resultados:}

Os resultados encontrados (veja tabela 3) mostram que em algumas das tarefas houve uma percentagem significante de pesquisados que não conseguiram cumprir o que foi pedido. Os ícones escolhidos foram os que obtiveram um nível de aceitação alto na parte I; contudo, é interessante notar que não foi possível eleger um único ícone que pudesse representar efetivamente sua respectiva tarefa. Observa-se também que na última tarefa pode-se perceber que a dúvida dos pesquisados foi maior, uma vez que a maioria não conseguiu concluir a tarefa.

Tabela 3. Resultados das tarefas.

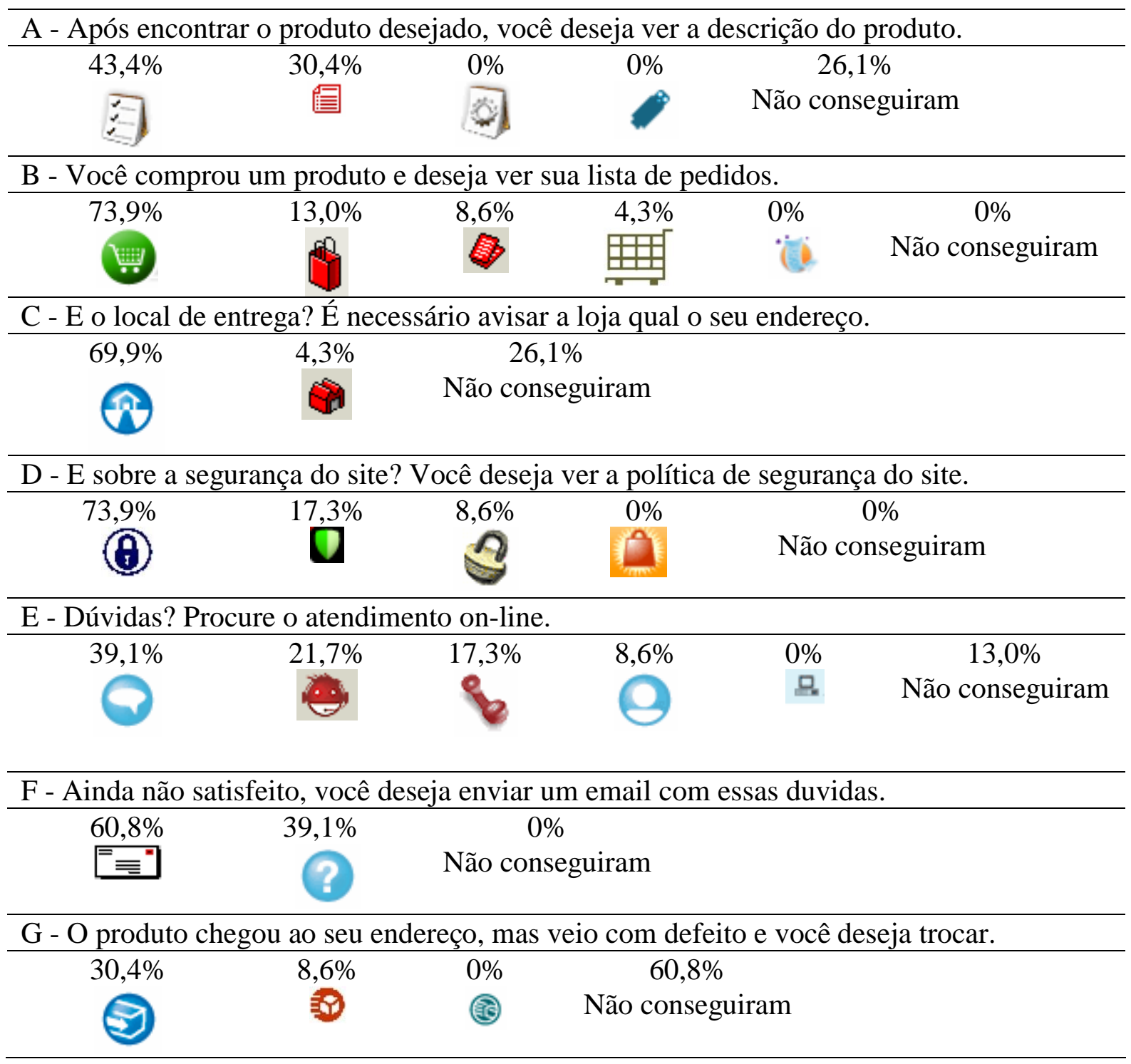




\subsection{Realização de testes - Parte II:}

Em seguida, o grupo de pesquisados realizaram as mesmas tarefas usadas no protótipo (tabela 3) em dois grandes sistemas de e-commerce brasileiros. O objetivo era de comparação e análise da usabilidade dos sites brasileiros. Ao final das tarefas foi pedido aos pesquisados que opinassem quanto à usabilidade dos sites, nas seguintes categorias: design, aparência, navegabilidade, qualidade da informação e consistência de funções. Foi usada uma escala, do tipo Likert, para que os pesquisados dessem notas: 0 - muito ruim; 1 - ruim; 2 - regular; 3 - boa, mas precisa melhorar; 4 - boa e 5 - ótima.

\subsection{Resultados:}

O tempo médio de realização das tarefas para o site I (ver tabela 4) e para o site II (ver tabela 5) encontram-se na tabela 4 abaixo. Observa-se que os tempos de execução são altos, e os sites foram considerados confusos e apresentaram problemas de usabilidade. Com o número crescente de opções, e facilidade de escolha, o usuário da Internet tende a uma impaciência maior, exigindo agilidade e qualidade. Não se pode supor que o usuário venha a gastar tempo em algo que seja confuso, lento, insatisfatório. A usabilidade do site é experimentada pelo usuário antes mesmo da compra do produto, e, portanto, tornou-se importante nos sites de e-commerce. [Nielsen 1999]

Tabela 4. Resultados das tarefas para o site I.

\begin{tabular}{|l|l|l|}
\hline Tarefa & Tempo médio & Problemas \\
\hline A & 2'20” & Funcionalidade. \\
\hline B & 2'30” & Funcionalidade; Ícones ininteligíveis. \\
\hline C & 3' & Site confuso. \\
\hline D & $4^{\prime}$ & Site pouco claro; Ícones ininteligíveis. \\
\hline E & $3^{\prime}$ & Site confuso. \\
\hline F & $3^{\prime}$ & Site confuso. \\
\hline G & 3'20’ & Site confuso. \\
\hline
\end{tabular}

Tabela 5. Resultados das tarefas para o site II.

\begin{tabular}{|l|l|l|}
\hline Tarefa & Tempo médio & Problemas \\
\hline A & $2^{\prime}$ & Funcionalidade; Site sem lógica. \\
\hline B & $5^{\prime}$ & Site confuso; Ícones não condizem com a funcionalidade. \\
\hline C & $2^{\prime}$ & Ícones ininteligíveis. \\
\hline D & $3^{\prime}$ & Site pouco claro; Ícones ininteligíveis. \\
\hline E & $1^{\prime}$ & Site confuso. \\
\hline F & $4^{\prime}$ & Site confuso. \\
\hline G & $3^{\prime}$ & Site confuso. \\
\hline
\end{tabular}


Quantos aos critérios de usabilidade (ver tabela 6), embora o site II tenha apresentado resultados um pouco melhores do que os resultados obtidos para o site I, ambos foram avaliados, em média, como sendo entre regular e bom, mas precisam melhorar.

Tabela 6. Resultados das tarefas para o site II

\begin{tabular}{|l|r|r|r|}
\hline Critério & \multicolumn{3}{|c|}{ Nota média } \\
\hline & Site I & 2,6 & Site II \\
\hline Design & 2,5 & 3,3 \\
\hline Aparência & 2,2 & 3,5 \\
\hline Navegabilidade & 2,8 & 2,9 \\
\hline Qualidade da Informação & 2,4 & 2,8 \\
\hline Consistência das funções & & 2,9 \\
\hline
\end{tabular}

\section{Conclusão:}

Observou-se, para o conjunto de ícones dos sites americanos, um consistente desencontro entre os significados atribuídos por americanos e brasileiros, sendo que os brasileiros reconheceram menos ícones que os americanos. Quanto ao conjunto de ícones usados em sites de e-commerce brasileiros, observou-se uma dificuldade grande dos pesquisados em entenderem o significado correto. Entretanto, os pesquisados puderam sugerir possíveis significados para estes ícones que parecem ser mais adequados. Acima de tudo, além da cultura, pode-se concluir, em ambos os casos, a falta de usabilidade dos ícones. Ressalta-se a necessidade de testes de usabilidade na determinação de um item tão importante em um site de e-commerce, uma vez que, se o usuário não consegue entender o significado do ícone do site, pode não conseguir usar e comprar neste site. E o usuário pode ir para um outro site de e-commerce facilmente.

Algumas tarefas foram realizadas a contento, com os ícones adequados tendo sido identificados. Por exemplo, para as tarefas B, C, D e F, os primeiros ícones da tabela 3 podem ser considerados como adequados. Estes ícones formam um conjunto indicado para uso, pelos analistas brasileiros, ao desenvolverem sites, para brasileiros, cuja interação visem à realização das respectivas tarefas. Este achado contribui para uma melhor efetividade dos sistemas de informação. Contudo, para as demais tarefas não se pôde concluir quais seriam os melhores ícones para representar efetivamente cada tarefa proposta.

A discrepância dos resultados entre culturas (americanos vs. brasileiros), e intra cultura (sites brasileiros vs. brasileiros) permite constatar, para trabalhos futuros, a necessidade de se ter um modelo padronizado de quais seriam os melhores ícones a serem usados em sites de e-commerce. Esta pesquisa deve ser ampliada, por exemplo, para englobar um conjunto maior de tarefas, e culturas, para oferecer aos desenvolvedores um conjunto de ícones identificáveis que possa ser usado para 
melhorar a usabilidade dos sites de e-commerce, promovendo assim um uso mais efetivo dos mesmos.

\section{Referências}

CAMARA-E.NET, (2007) “Gastos com bens de consumo, turismo e automóveis pela internet somaram $R \$ 4,4$ bilhões no $1^{\circ}$ trimestre" Website: www.camarae.net/interna.asp?tipo=1\&valor=4114 acessado outubro 2007.

CARROLL, J.M. e MORAN, T.P. (1996) “Design Rationale: concepts, techniques, and use.", New Jersey: LEA.

CHENG, HI e PATTERSON, P.E. (2006) “Iconic hyperlinks on e-commerce websites”, Website Www.elsevier.com/locate/apergodoi:10.1016/ j.apergo.2006.01.007 acessado 25/05/2007.

GUIMARÃES, C. (2000) “Usability Via/For Internet”. Dissertation (M.Sc.). Blackgsburg, VA. Virginia Tech.

LODDING, K.N. (1983).”Iconic Interface”. IEEE Comp. Graphics Appl. 3(2), 11-12.

NIELSEN, J. (1999) “Design Web Usability” Ind., IN: New Riders Publishing.

NISBETT,R. e CHUA, H.F. (2005) "Chineses e Americanos enxergam mesma imagem de modo distinto". Website http://www-personal.umich.edu/ nisbett/ acessado 25/05/2007.

NORMAN, D. (2007) Website www.jnd.org acessado 25/05/2007.

PALLOTTA, L (2007). “ESTATÍSTICA: O Brasil Online” (2007) website http://emarketingvox.blogspot.com/2007/06/estatstica.html acessado outubro 2007.

PONTES, A.M. e ORTH, A.I. (2001) "Proposta e validação de método para estudo da percepção de signos por sujeitos inseridos em diferentes meios culturais” In Anais do IHC 2001. IV Workshop sobre F.H. em Sistemas Computacionais.

ROGERS,Y.(1986) "Evaluating the meaningfulness of icon sets to represent command operations. In. Human Factors in Comp. Systems: Proceedings of CHI '86 pp. 586603.

SCAPIN, D.L. (1993) “The need for a psycho-engineering approache to HCI”, In: Anais do Segundo congresso latino-americano e sexto seminário brasileiro de ergonomia. Florianópolis (Santa Catarina), ABERGO/FUNDACENTRO, 03-22.

STANDING, L., CONEZIO, J., HABER, R.N. (1970) "Perception and memory for pictures”. Psychon Sci. 19, 73-74.

YUKI, M. (2007) "Cultural differences in emotion recognition" website http://lynx.let.hokudai.ac.jp/ myuki/ acessado 25/05/2007. 